\title{
Pre-clinical Activity of Tipifarnib in Cutaneous T-cell Lymphoma
}

\section{Introduction}

Cutaneous T-cell lymphoma (CTCL) is a rare form of nonHodgkin lymphoma characterized by malignant infiltration of skinhoming CD4+ T-cells, manifesting clinically as patches and plaques on the skin. The disease will often progress from an indolent skin-limited form, Mycosis Fungoides (MF), to an aggressive leukemic variant, Sezary Syndrome (SS).

As there are few effective therapies available for advanced-stage CTCL, we sought to explore potential novel therapeutic modalities. Farnesyl transferase inhibitors (FTls) are a relatively new class of anticancer drugs, the exact mechanism of which is unknown. Tipifarnib is one such FTI, which has demonstrated clinical activity as a single agent in patients with relapsed and refractory lymphomas. Despite encouraging clinical and preclinical data, the precise molecular mechanisms of tipifarnib's activity in lymphoma remain to be fully elucidated.

\section{Methods and Results}

We utilized CTCL patient-derived cell lines to evaluate the potential efficacy of tipifarnib in vitro. Our data on patient-derived cell lines show that half maximal effective concentration $\left(E_{50}\right.$ ) ranged from 7.5nM for HuT78 to $50 \mathrm{nM}$ for SeAx (Figure 1A). This cytotoxicity was correlated to increases in apoptosis in these lines (Figure 1B). Importantly, there was no cytotoxic effect on normal donor CD4+ T-cells in vitro (data not shown). Based on these promising findings, we evaluated tipifarnib in vivo using a recently described interleukin-15 (IL-15) transgenic mouse model of CTCL (Mishra A, et al. Can Discov 2016). Following 2 weeks of dosing in 5 week old mice, we found a significant decrease in gross lesion severity in tipifarnib-treated mice $(0.5 \pm 1.22$ out of a possible score of 5$)$ compared to vehicletreated mice $(3.33 \pm 0.57, \quad \mathrm{p}=0.0076)$ (Figure 2A, 2B) Histologically, IL-15 transgenic mice develop characteristic malignant CD4+ T-cell infiltrates in the dermis and epidermis (Figure 3A). Tipifarnib-treated mice, however, have minima lesions in the skin (Figure 3A, bottom). These dramatic changes are reflected in a significantly decreased histologic severity score in tipifarnib-treated mice (3.8 \pm 0.75 out of a possible score of 7$)$ compared to vehicle-treated mice $(7 \pm 0, p=0.0002)$ (Figure 3B).

\section{Results}

Figure 1. Tipifarnib, a farnesyl transferase inhibitor, decreases cell viability and increases apoptosis in CTCL lines in vitro
(A)

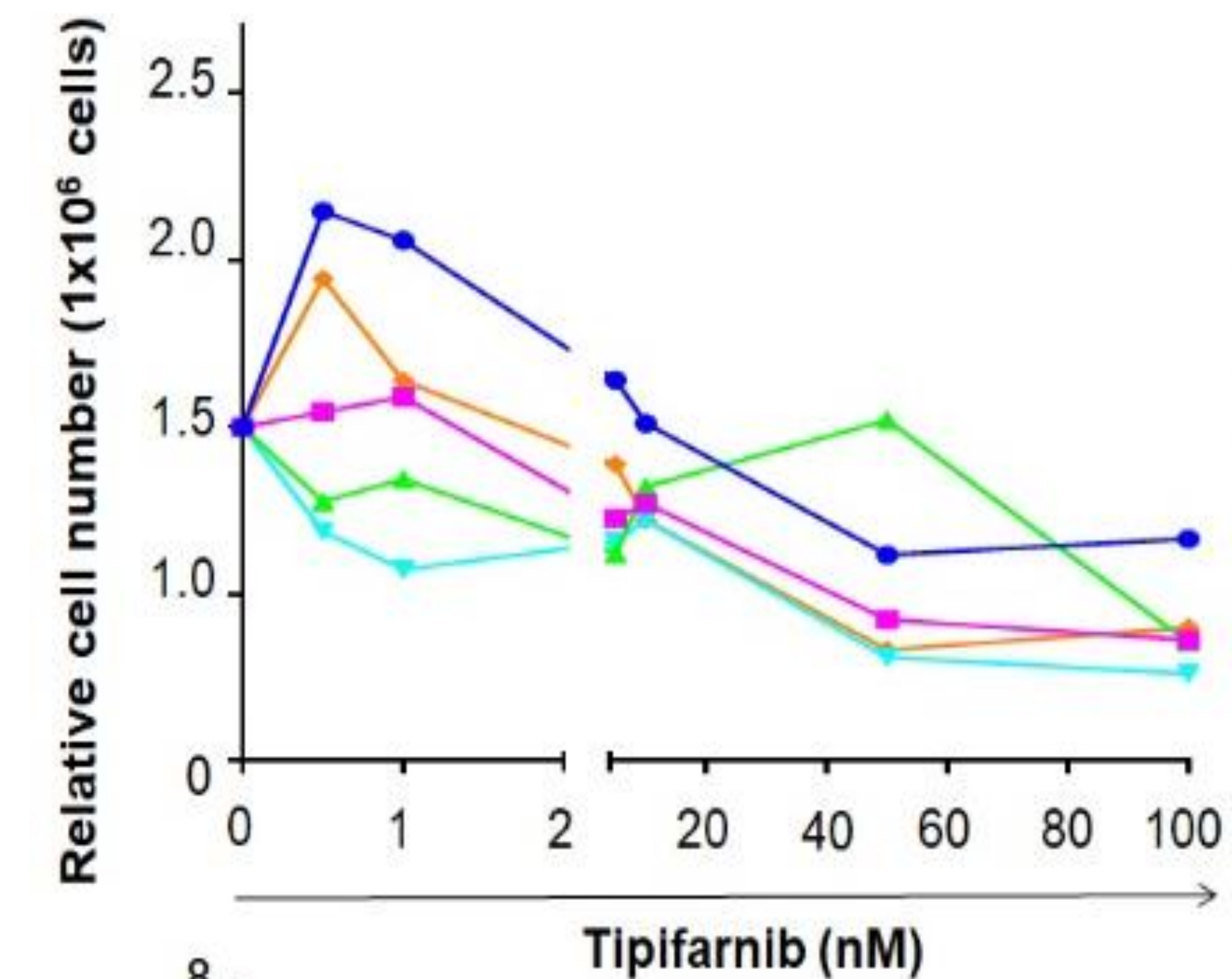

(B)

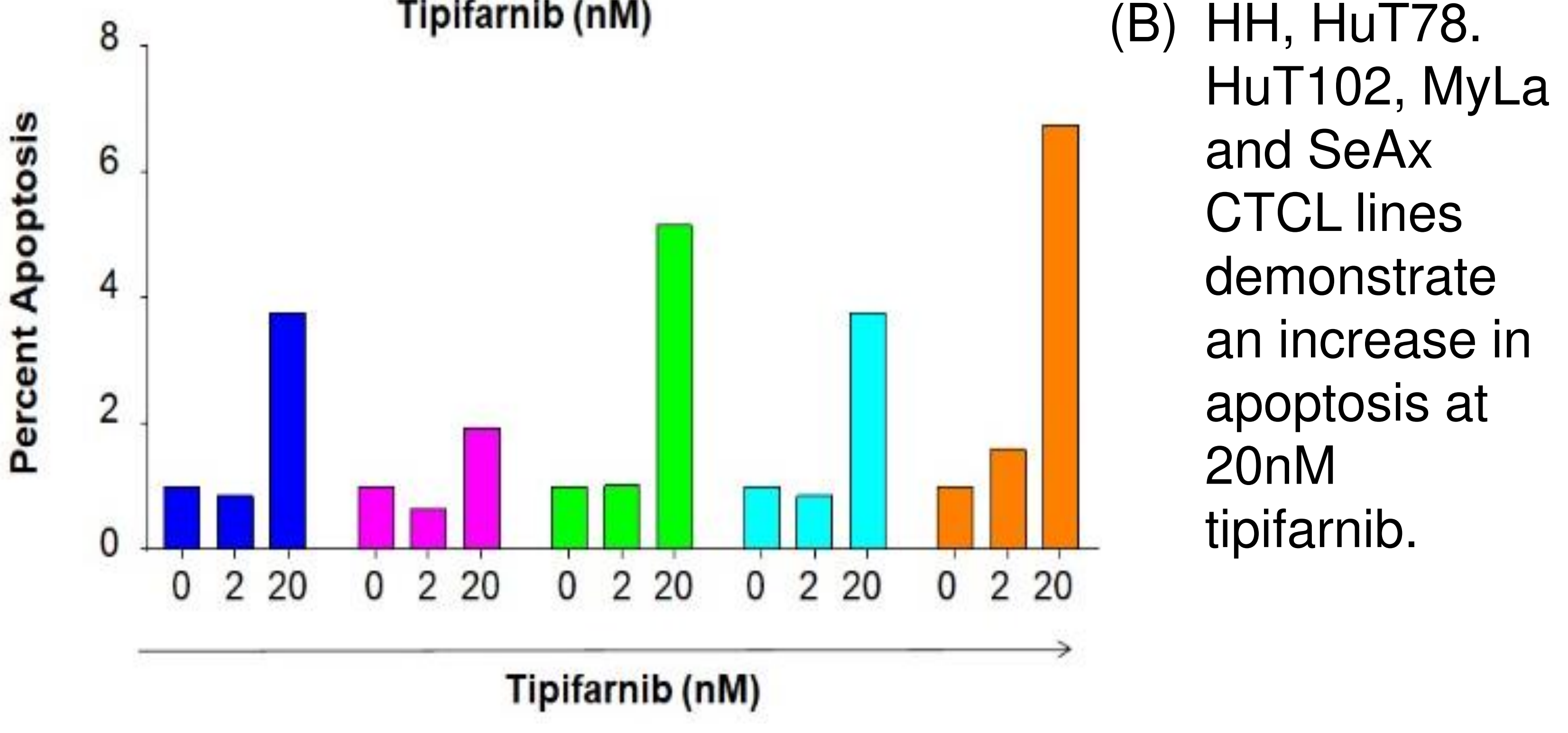

Figure 2. Tipifarnib treatment in vivo decreases CTCL disease severity in IL-15 transgenic mice

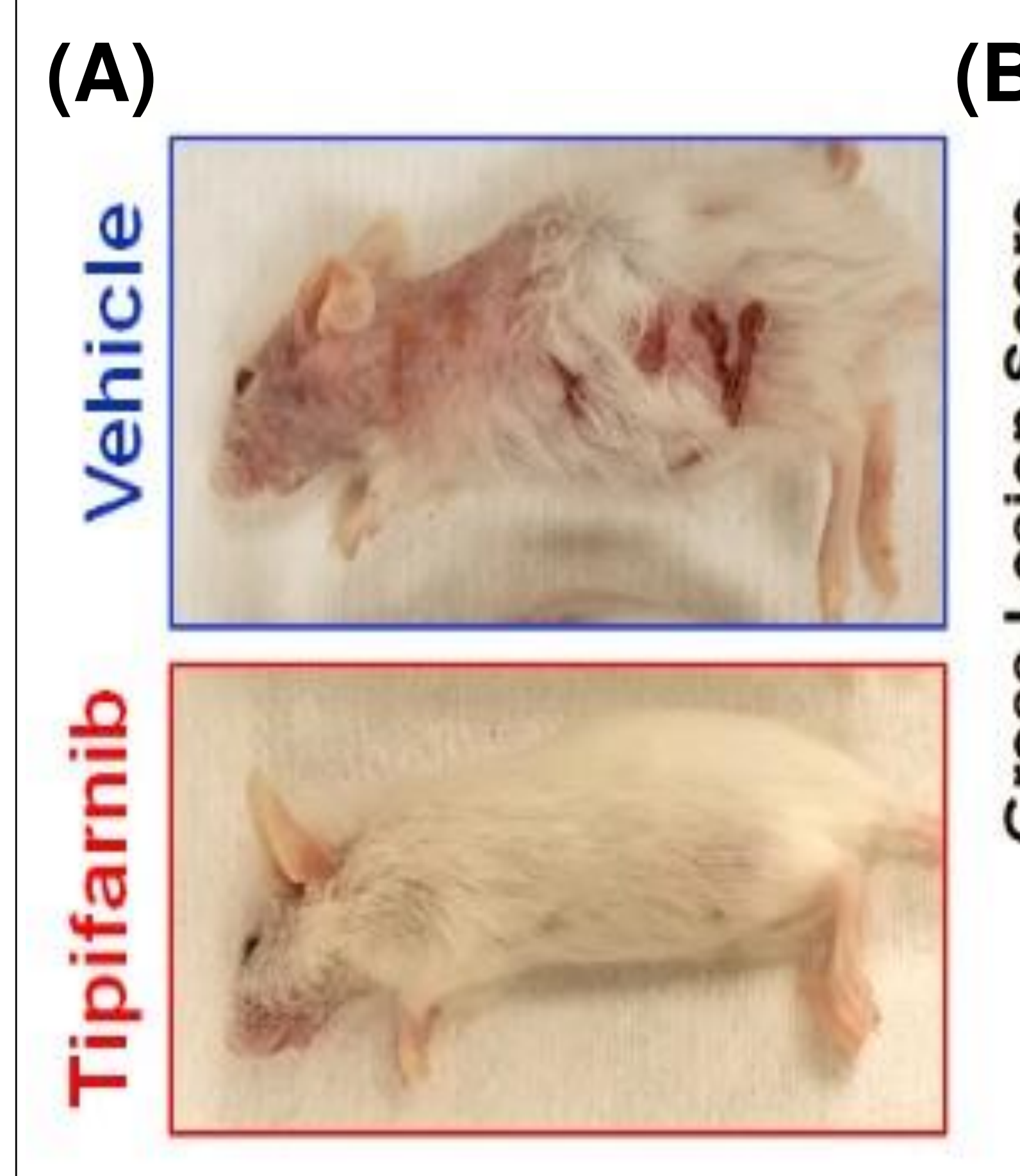

(A) Dose escalation tipifarnib in vitro, demonstrate decreased cel viability in CTCL parent lines.

B) $\mathrm{HH}, \mathrm{HuT78}$ HuT102, MyLa and SeAx demonstrate onM mice treated with tipifarnib extensive cutaneous disease.

(B) Gross lesion severity treated mice treated mice,
as compared $\begin{array}{ll}\text { as } & \text { compared } \\ \text { to vehicle- }\end{array}$

\section{Results}

Figure 3. Tipifarnib treatment in vivo decreases histologic lesion severity in IL-15 transgenic mice
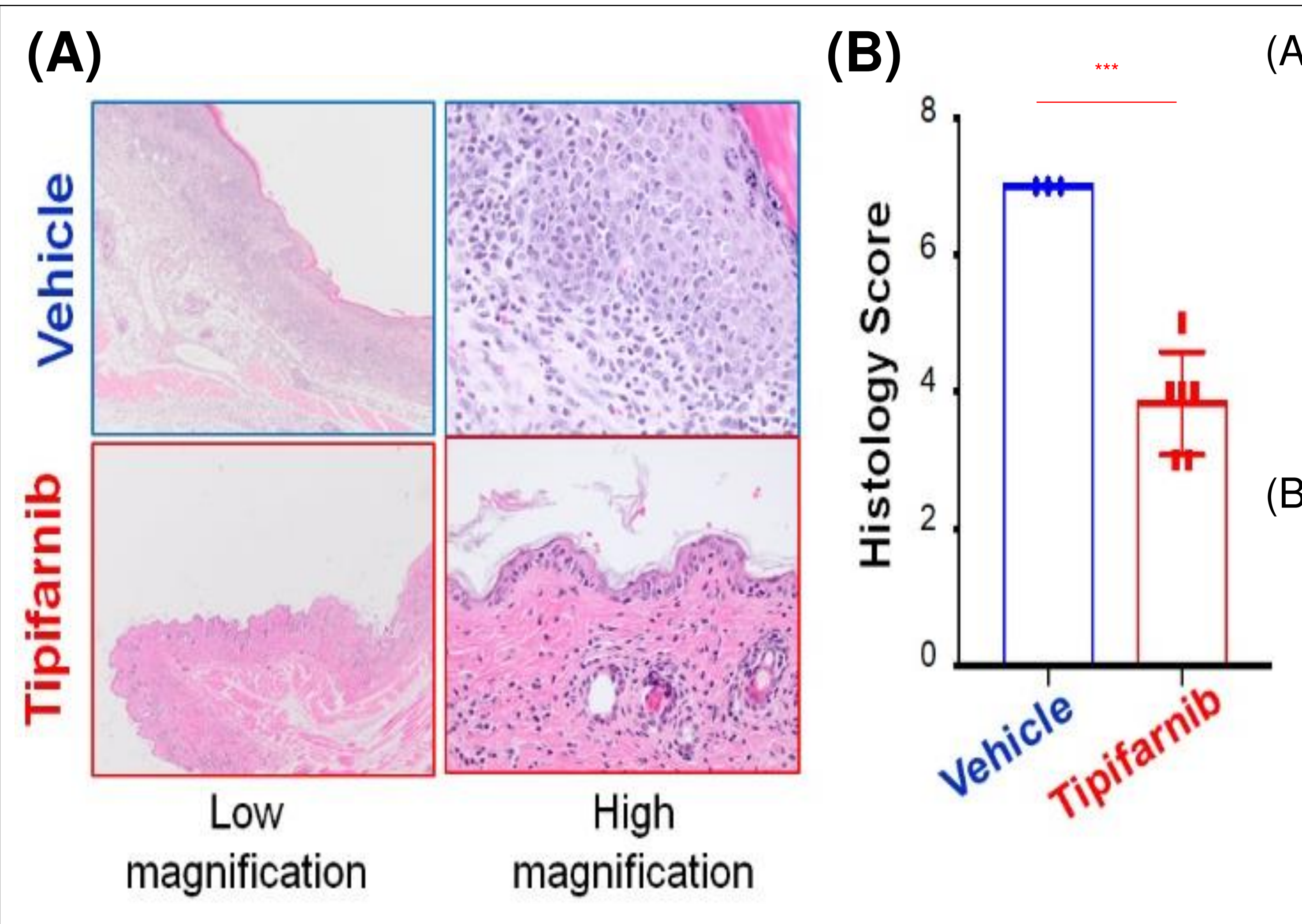

(A) Tipifarnibtreated mice lesions CTCL compared to vehicletreated mice.

Histologic lesion severity is significantly
reduced in reduced treated mice.

\section{Conclusions}

Our findings demonstrate that tipifarnib may prove beneficial for the treatment of CTCL as shown in efficacy observed in patient derived cell lines and mouse models of cutaneous T-cell lymphoma. Further studies to elucidate the mechanism of antitumor activity of farnesyl transferase inhibition in malignant T-cells are in progress.

Authors declare no conflicts of interest.

De-identified patient materials provided by OSUCC Leukemia Tissue Bank Shared Resource (P30CA016058).

Funding for this project by Kura Oncology to AM.

References: treated mice.

A, La Pelle K, Kwiatkowski S, Sullivan L, Sams GH, Johns J, Curphey DP, Wen J, McConnell K, Qi J, Wong H, Russo G, Zhang J, Marcucci G, Bradner JE, Porcu P, Caligiu $M A$. Mechanism,

2. Witzig T, Tang H, Micallef I, Ansell S, Link B, Inwards D, Porrat L, Johnston P, Colgan J, Kurtin P, Ding H, Loegering D, Schneider P, Peterson K, Habermann T, Kaufmann S. Multiinstitutional phase 2 study of the farnesyl transferase inhibitor tipifarnib (R115777) in patients with relapsed and refractory lymphomas. Blood 2011 Nov; 118(18): 4882-4889.

Sparano J, Moulder S, Kazi A, Coppola D, Negassa A, Vahdat L, Li T, Pellegrino C, Fineberg S, Munster P, Malafa M, Lee D, Hoschander S, Hopkins U, Hershman D, Wright J, Kleer C, Merajver $\mathrm{S}$, Sebti $\mathrm{S}$. Phase II trial of the farnesyl transferase inhibitor tipifarnib plus neoadjuvant doxorubicin-cyclophosphamide in patients wht 